\title{
Thermal analysis of bulk filled composite resin polymerization using various light curing modes according to the curing depth and approximation to the cavity wall
}

\author{
Hoon-Sang CHANG ${ }^{1}$, Kyu-Jeong $\mathrm{CHO}^{2}$, Su-Jung PARK ${ }^{3}$, Bin-Na LEE ${ }^{4}$, Yun-Chan HWANG' ${ }^{1}$, Won-Mann $\mathrm{OH}^{5}$, In-Nam \\ HWANG ${ }^{5}$
}

\footnotetext{
1- DDS, MS, PhD, Associate Professor, Department of Conservative Dentistry and Dental Science Research Institute, School of Dentistry, Chonnam National University, Gwangju, Korea.

2- DDS, MS, Postgraduate student, Department of Conservative Dentistry, School of Dentistry, Chonnam National University, Gwangju, Korea.

3- DDS, MS, Assistant Professor, Department of Conservative Dentistry, Dental Research Institute, College of Dentistry, Wonkwang University, Iksan, Jeonbuk, Korea.

4- DDS, MS, Clinical Fellow, Department of Conservative Dentistry, Dental Science Research Institute, School of Dentistry, Chonnam National University, Gwangju, Korea.

5- DDS, MS, PhD, Professor, Department of Conservative Dentistry and Dental Science Research Institute, School of Dentistry, Chonnam National University, Gwangju, Korea.
}

Corresponding address: In-Nam Hwang - Department of Conservative Dentistry - School of Dentistry - Chonnam National University - Yongbong-dong, Buk-gu - Gwangju - Korea - Phone +82-62-530-5819 - Fax. +82-62-530-5829 - e-mail: hinso@chonnam.ac.kr

Submitted: January 9, 2013 - Modification: May 14, 2013 - Accepted: May 24, 2013

\section{ABSTRACT}

\begin{abstract}
bjective: The purpose of this study was to investigate the polymerization temperature of a bulk filled composite resin light-activated with various light curing modes using infrared thermography according to the curing depth and approximation to the cavity wall. Material and Methods: Composite resin (AeliteFlo, Bisco, Schaumburg, IL, USA) was inserted into a Class II cavity prepared in the Teflon blocks and was cured with a LED light curing unit (Dr's Light, GoodDoctors Co., Seoul, Korea) using various light curing modes for $20 \mathrm{~s}$. Polymerization temperature was measured with an infrared thermographic camera (Thermovision 900 SW/TE, Agema Infra-red Systems AB, Danderyd, Sweden) for $40 \mathrm{~s}$ at measurement spots adjacent to the cavity wall and in the middle of the cavity from the surface to a $4 \mathrm{~mm}$ depth. Data were analyzed according to the light curing modes with one-way ANOVA, and according to curing depth and approximation to the cavity wall with two-way ANOVA. Results: The peak polymerization temperature of the composite resin was not affected by the light curing modes. According to the curing depth, the peak polymerization temperature at the depth of $1 \mathrm{~mm}$ to $3 \mathrm{~mm}$ was significantly higher than that at the depth of $4 \mathrm{~mm}$, and on the surface. The peak polymerization temperature of the spots in the middle of the cavity was higher than that measured in spots adjacent to the cavity wall. Conclusion: In the photopolymerization of the composite resin, the temperature was higher in the middle of the cavity compared to the outer surface or at the internal walls of the prepared cavity.
\end{abstract}

Key words: Composite resins. Dental curing lights. Polymerization. Thermography.

\section{INTRODUCTION}

Light curing of composite resin induces polymerization shrinkage, which leads to residual stress in the final restoration. The level of stress can have significant clinical consequences, including crack formation in the enamel or microscopic separations at the preparation/ restoration interface ${ }^{23}$. Davidson and Feilzer ${ }^{7}$ (1997) reported that slow curing of composite resin reduced polymerization shrinkage by relieving stress. Similarly, pulse-delay polymerization is 
initiated by a short flash of curing light followed by a waiting time of several minutes before the final cure is performed ${ }^{1,13,20,23}$. Soft-start curing is initiated with a reduced power density during the first part of the polymerization period in order to reduce polymerization shrinkage stress ${ }^{1,4,6,29}$. These methods have been reported to reduce the gap formation between the tooth structure and the composite resin without compromising the mechanical properties or degree of conversion ${ }^{17-19,27}$.

Despite using various light curing modes, the temperature of the composite resin is increased during photopolymerization ${ }^{3,8}$. Previous studies showed a temperature rise of more than $20^{\circ} \mathrm{C}$ in the composite resin during light curing ${ }^{10,15}$. The temperature rise is more prominent when the curing time is long, light intensity is high, the composite resin is massive, and the degree of conversion of the composite resin is high ${ }^{15}$. Zach and Cohen $^{28}$ (1965) reported that this temperature rise during light-activation of composite resins could induce a significant adverse pulpal reaction in animal models. However, Al-Qudah, et al. ${ }^{2}$ (2005) reported that dentin disks worked as good thermal insulators against exothermic reactions of the composite resins.

In the in vitro studies, the temperature rise during polymerization of the composite resin has been measured by the use of thermistor ${ }^{22}$, thermocouples ${ }^{8,14}$, differential scanning calorimetry ${ }^{25}$, and differential thermal analysis ${ }^{16,26}$. Observations have indicated temperature rises of between 3.3 and $40^{\circ} \mathrm{C}$ during composite resin polymerization. Unfortunately, these methods are invasive as they involve contact with the surface under study, which will alter the temperature recording accuracy. By contrast, electronic infrared thermography is a non-contact recording modality which is accurate and sensitive enough to record $0.1^{\circ} \mathrm{C}^{12}$. It, therefore, has advantages over other methods of temperature measurement. Hussey, Biagioni and Lamey ${ }^{12}$ (1995) utilized this technique in vivo and measured the heat generated during light curing of a composite resin.

Previous studies measured the temperature in the lower surface of the composite resin specimens of various thicknesses with electronic infrared thermography while light curing of the upper surface ${ }^{2,3}$. In this manner, only the temperature of the lower surface could be measured and the temperature within the composite resin could not be measured. In this study, however, the polymerization temperature was measured on the upper surface while the proximal surface of the composite resin was light activated. Therefore, the temperature within the composite resin, from the proximal surface to the deeper parts of the composite resin, could be measured according to the curing depth.

The aim of the present study was to evaluate the peak polymerization temperature of bulk filled composite resin according to the light curing modes. Then, the peak polymerization temperature at the selected measurement spots was evaluated according to the curing depth and approximation to the cavity wall. Therefore, the null hypotheses to be tested were: 1) the peak polymerization temperature of a composite resin is not affected by the various light curing modes; 2) the peak polymerization temperature of a composite resin at the selected measurement spots is not significantly different.

\section{MATERIAL AND METHODS}

A Class II cavity, $5 \mathrm{~mm}$ in length, $5 \mathrm{~mm}$ in width, and $4 \mathrm{~mm}$ in depth, was prepared in rectangular Teflon blocks. In order to determine the temperature measurement spots on the upper surface of the composite resin, a copper plate identical in size to the cavity in the Teflon block was positioned on a squared table and heated. A thermographic image of the heated copper plate was taken and the temperature measurement spots were determined. Spots 1 to 5 were assigned adjacent to the cavity wall and spots 6 to 10 were assigned in the middle of the cavity according to the curing depth. Spots 1 and 6 were assigned at the proximal end of the cavity and the spots 2 to 5 and 7 to 10 were assigned deep into the cavity from the proximal surface at 1-mm intervals (Figure 1A). The cavity was filled with an A2 shade flowable resin (AeliteFlo, Bisco, Schaumburg, IL, USA) while the proximal end of the cavity was covered with a microscopic slide glass so as to limit the composite resin within the cavity. The Teflon blocks could be placed in the same position as the copper plate for the thermographic image taking by referencing the squared table.

The light guide of a light emitting diode (LED) based light curing unit (LCU) (Dr's Light, GoodDoctors Co., Seoul, Korea) was fixed with a custom made clamp attached to a retort stand 1 $\mathrm{mm}$ away from the open proximal surface of the Teflon block. The exit window of the light guide was positioned parallel to the proximal surface. Then, the composite resin was light cured with various output modes for $20 \mathrm{~s}$ : normal mode, high mode, pulse mode, soft-start mode, and pulse soft-start mode. Therefore, ten recordings were acquired for each composite resin specimen and five recordings were acquired at each measurement spot. Two composite resin specimens were used to measure the polymerization temperature of the composite resin with each light curing mode.

While the composite resin was light cured 
at the proximal surface, the polymerization temperature was measured at the upper surface. A radiation shield was installed over the proximal surface in order to prevent light curing of the composite resin at the upper surface where the polymerization temperature was measured (Figure 1B). The polymerization temperature of the composite resin was measured from the start of light activation with an infrared thermographic camera (Thermovision 900 SW/TE, Agema Infrared Systems AB, Danderyd, Sweden) for $40 \mathrm{~s}$ at room temperature. The polymerization temperature of each measurement spot was recorded in five frames per second and converted to temperature per second.

The peak polymerization temperature of the composite resin according to the light curing modes was analyzed with one-way ANOVA at a 0.05 significance level followed by post-hoc comparisons with the Tukey's HSD test (SPSS 18.0, SPSS

A
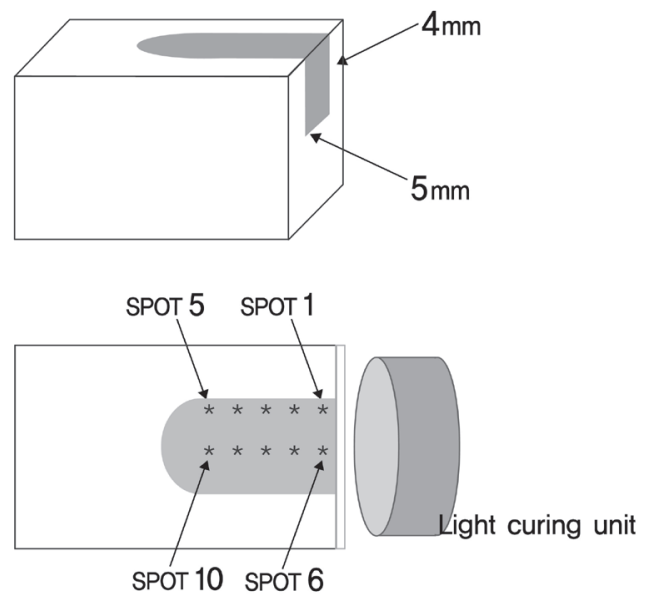

B

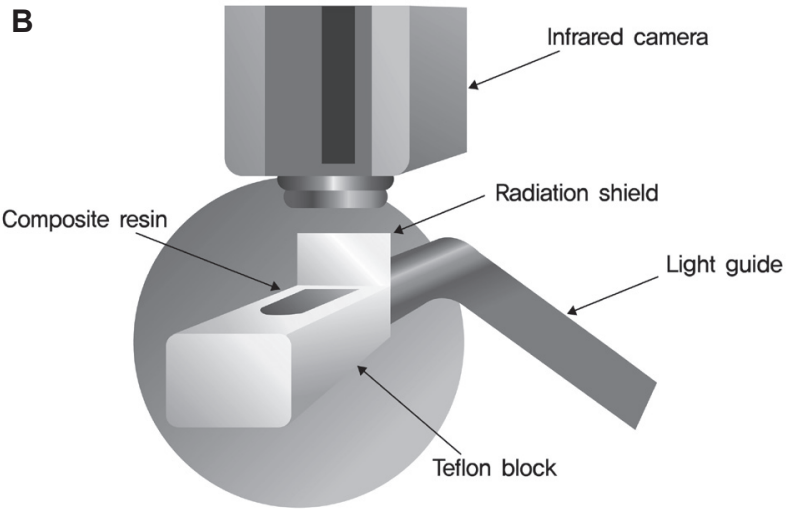

Figure 1- (A) Schematic diagram of the temperature measurement spots from spot 1 to 10. (B) Schematic diagram of infrared thermographic measurement of temperature change in the composite resin during photopolymerization. The infrared thermographic camera was located above the composite resin in a Teflon block. A radiation shield was used to limit the radiation of the light guide only to the proximal surface of the composite resin
Inc., Chicago, IL, USA). The peak polymerization temperature of the measurement spots within the composite resin (approximation to the cavity wall and curing depth) was analyzed with two-way ANOVA at a 0.05 significance level followed by posthoc comparisons with the Tukey's HSD.

\section{RESULTS}

The mean peak polymerization temperature of the composite resin according to the light curing modes was $51.0 \pm 11.9^{\circ} \mathrm{C}$ with the normal mode, $58.6 \pm 13.8^{\circ} \mathrm{C}$ with the pulse mode, $58.6 \pm 13.1^{\circ} \mathrm{C}$ with the soft start mode, $60.2 \pm 12.8^{\circ} \mathrm{C}$ with the pulse soft start mode, and $60.6 \pm 12.9^{\circ} \mathrm{C}$ with the high mode in an increasing order (Figure 2 ). There were no statistically significant differences in the peak polymerization temperature of the composite resin between the light curing modes ( $p>0.05)$.

The mean peak polymerization temperature of the selected measurement spots according to the approximation to the cavity wall and curing depth is shown in Table 1 . The two-way ANOVA showed a significant effect for both the main factors (approximation to the cavity wall, $\mathrm{p}<0.001$; curing depth, $p<0.001)$ and their interaction $(p=0.014)$.

When comparing the measurement spots according to the approximation to the cavity wall and curing depth, the peak polymerization temperature measured adjacent to the cavity wall was significantly higher at depths of $2 \mathrm{~mm}$, $3 \mathrm{~mm}, 1 \mathrm{~mm}$, and $4 \mathrm{~mm}$ than that measured on the surface $(p<0.05)$. The peak polymerization temperature measured in the middle of the cavity was significantly higher at depths of $2 \mathrm{~mm}, 1 \mathrm{~mm}$, and $3 \mathrm{~mm}$ followed by that measured at the depth of $4 \mathrm{~mm}$, and by that measured on the surface $(p<0.05)$.

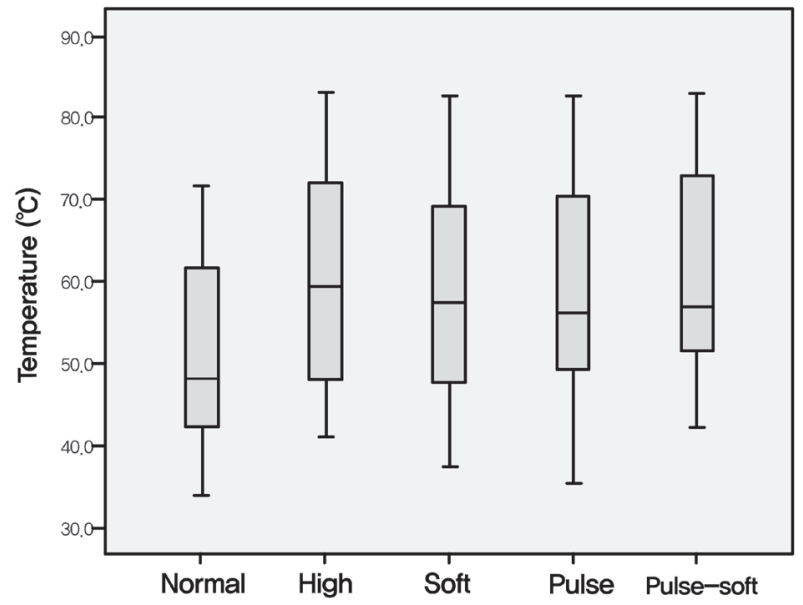

Figure 2- Mean peak polymerization temperature $\left({ }^{\circ} \mathrm{C}\right)$ of composite resin specimens at the selected spots according to the light curing modes of light emitting diode light curing unit $(p>0.05)$ 
Table 1- Mean and standard deviation values of peak polymerization temperature $\left({ }^{\circ} \mathrm{C}\right)$ of composite resin specimens at the selected spots

\begin{tabular}{ccc}
\hline Measurement spots & Adjacent to the cavity wall & In the middle of the cavity \\
\hline Surface & $39.7 \pm 4.0^{\mathrm{A}, \mathrm{a}}$ & $51.7 \pm 6.6^{\mathrm{A}, \mathrm{b}}$ \\
1 mm depth & $50.0 \pm 6.1^{\mathrm{B}, \mathrm{a}}$ & $72.9 \pm 6.9^{\mathrm{C}, \mathrm{b}}$ \\
2 mm depth & $54.0 \pm 6.7^{\mathrm{B}, \mathrm{a}}$ & $76.9 \pm 5.5^{\mathrm{C}, \mathrm{b}}$ \\
3 mm depth & $52.0 \pm 6.3^{\mathrm{B}, \mathrm{a}}$ & $71.4 \pm 5.4^{\mathrm{C}, \mathrm{b}}$ \\
4 mm depth & $47.4 \pm 5.3^{\mathrm{B}, \mathrm{a}}$ & $62.2 \pm 6.4^{\mathrm{B}, \mathrm{b}}$ \\
\hline
\end{tabular}

*Values followed by the same letters are not significantly different $(p<0.05)$. Uppercase letters were used to compare groups in the columns; lowercase letters were used to compare groups in the rows

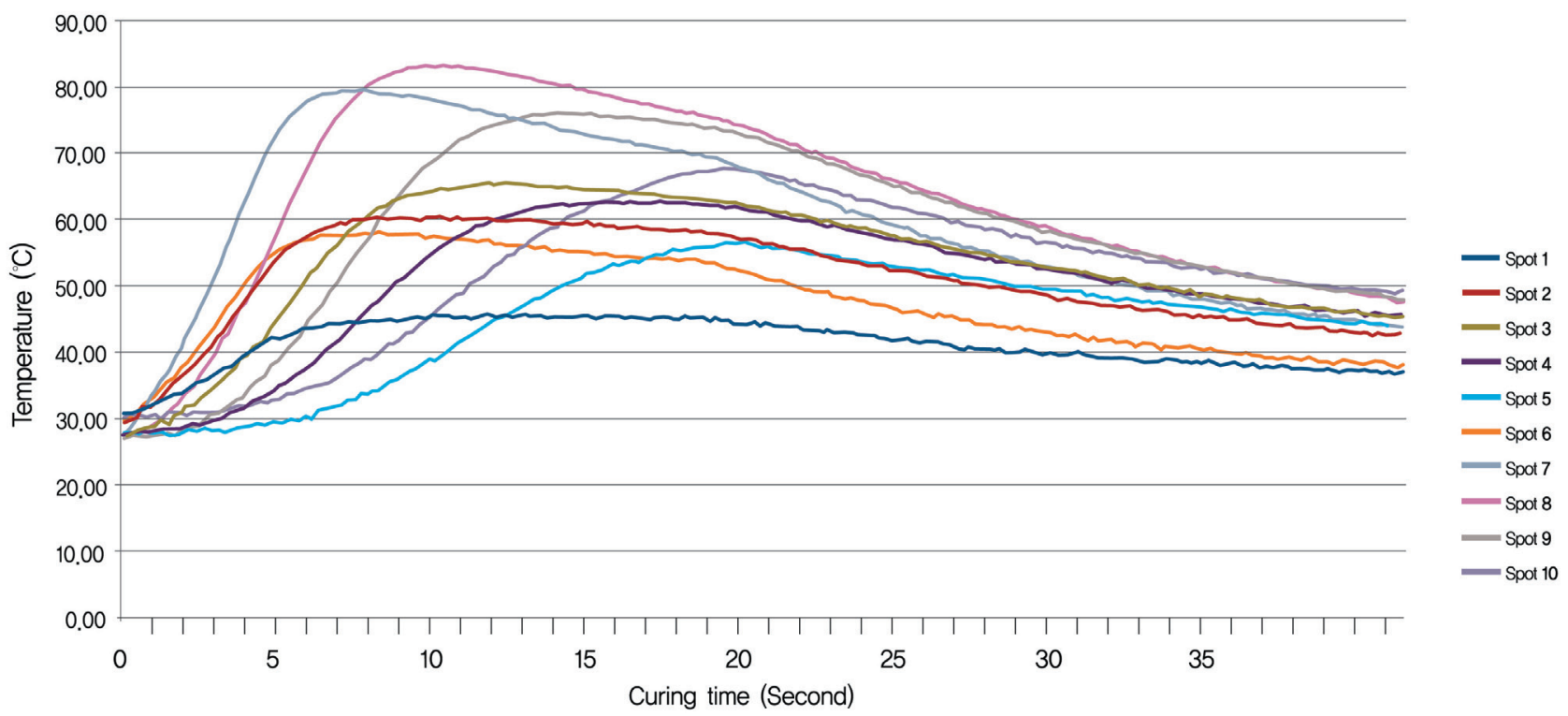

Figure 3- Representative polymerization temperature curves of composite resin light cured with high mode of light emitting diode light curing unit at the selected spots

Figure 3 represents the polymerization temperature curves of the composite resin light cured with high mode of LED LCU at the selected spots. The peak polymerization temperature at spots 7, 8, and 9 was significantly higher than the peak polymerization temperature at the other spots.

\section{DISCUSSION}

Some LED based LCUs are equipped with different output modes: normal mode, high mode, pulse mode, soft-start mode, and pulse soft-start mode. One of these LCUs is the Dr's Light. According to the manufacturer, the power density of this LCU was $600 \mathrm{~mW} / \mathrm{cm}^{2}$ in the normal mode and was $1200 \mathrm{~mW} / \mathrm{cm}^{2}$ in the high mode. The pulse mode consisted of irradiation with $1200 \mathrm{~mW} / \mathrm{cm}^{2}$ for 0.1 $\mathrm{s}$ and $\mathrm{a} 0.05 \mathrm{~s}$ pause alternating for $20 \mathrm{~s}$. The softstart mode consisted of increasing power density from 0 to $600 \mathrm{~mW} / \mathrm{cm}^{2}$ for $5 \mathrm{~s}$ and thereafter in full strength of $1200 \mathrm{~mW} / \mathrm{cm}^{2}$ for $15 \mathrm{~s}$. The pulse softstart mode consisted of increasing power density from 0 to $600 \mathrm{~mW} / \mathrm{cm}^{2}$ for 0.1 second and a 0.05 $\mathrm{s}$ pause alternating for $5 \mathrm{~s}$, and thereafter, in full strength of $1200 \mathrm{~mW} / \mathrm{cm}^{2}$ for $15 \mathrm{~s}$. The final power density of each light curing mode was checked with a hand held dental radiometer (Cure Rite, Kerr, Milford, MA, USA).

The temperature rise during light curing of the composite resin is a function of the rate and degree of conversion of carbon-carbon double bonds to carbon-carbon single bonds ${ }^{2,8}$. The prominent temperature rise observed in this study indicates a high rate of photopolymerization, since the exothermic reaction is proportional to the amount of resin available for polymerization ${ }^{2,3,12}$. The peak polymerization temperature at the measurement spots was between $39.7^{\circ} \mathrm{C}$ to $76.9^{\circ} \mathrm{C}$. The peak temperature was over $50^{\circ} \mathrm{C}$ in all measurement spots in the middle of the cavity. This result is in accordance with the result of a previous study reporting a maximum peak polymerization temperature of more than $50^{\circ} \mathrm{C}$. The high polymerization temperature in this study 
may be mainly due to the power density of the LCU, filler content of the composite resin and the mass of the composite resin. Hannig and Bott $^{9}$ (1999) reported that LCUs with a high energy output caused a significantly higher temperature rise in the composite resin than that caused by LCUs with a lower energy output. In their study, an LCU with a power density of $320 \mathrm{~mW} / \mathrm{cm}^{2}$ induced a significantly lower temperature rise in the composite resin compared to that caused by an with a power density of more than $500 \mathrm{~mW} / \mathrm{cm}^{2}$. In their study, halogen based LCUs are used and they are reported to increase the polymerization temperature of composite resin due to the heating effect of the light source ${ }^{2}$. However, in our study, a LED based LCU was used and the LED LCU is reported to have minimal heating effect ${ }^{10}$. Therefore, the temperature rise of the composite resin light cured with various light curing modes was prominent, and it could be extrapolated that the power density of at least 600 $\mathrm{mW} / \mathrm{cm}^{2}$ (normal mode) was sufficient for proper light curing of the composite resin. Hubbezoglu, et al. ${ }^{11}$ (2008) reported that flowable resins with low filler content showed higher temperature rise than that in the hybrid composites with the same filler size distribution. The flowable resin used in our study contained 56 wt. \% barium glass filler, which was even lower than the filler content of the flowable resin used in their study. Al-Qudah, et al. $^{3}$ (2007) reported a temperature rise of up to $41.1^{\circ} \mathrm{C}$ for a flowable resin with $25 \%$ less filler content than that of hybrid composite resin. Also, previous studies have reported that the exothermic reaction of the composite resin is proportional to the amount of resin available for polymerization ${ }^{2,3,12}$. In our study, the polymerization temperature of a large bulk of flowable resin was measured and a prominent temperature increase was observed in the composite resin.

In the first part of this study, the mean peak polymerization temperature of the composite resin was not affected by various light curing modes. Therefore, the first null hypothesis was accepted. Hoffman, Hugo and Klaiber ${ }^{10}$ (2002) investigated the temperature rise during polymerization of the composite resin and reported that there were no significant differences between the continuous mode and the ramp mode of the LED LCU. However, another study reported that the peak polymerization temperature of a hybrid composite resin light cured with a halogen LCU in the ramp mode was lower than that of a hybrid composite resin light cured with a halogen LCU in the conventional mode ${ }^{3}$. The halogen LCUs are reported to have a heating effect on the composite resin ${ }^{2}$ and the conventional mode of the halogen LCU with full power density from the start of light curing could have affected the peak polymerization temperature. The ramp mode of the halogen LCU used in their study began at a power density of $100 \mathrm{~mW} / \mathrm{cm}^{2}$ to the maximum power density for $10 \mathrm{~s}$ and the heating effect could have been suppressed for that time period. In contrast, LED LCUs are reported to have a low heating effect ${ }^{10}$. In addition, in the soft-start and pulse soft-start modes of the LED LCU used in this study, the time between the initial power density and the maximum power density was only $5 \mathrm{~s}$, and thus, there was less time for the suppression of the heating effect compared with $10 \mathrm{~s}$ of the halogen LCU as described above. Therefore, it could be assumed that the difference in the light source of the LCU and the program setting of the light curing mode may have contributed to the difference in the polymerization temperature of the composite resin. Since Al-Qudah, et al.² (2005) stated that exothermic reaction of composite resin polymerization is proportional to the degree of conversion of carbon-carbon double bonds, and there were no significant differences in the peak polymerization temperature of the composite resin according to the light curing modes, it could be assumed that the degree of cure was high ${ }^{8}$.

While comparing the measurement spots adjacent to the cavity wall, the peak polymerization temperature on the surface was significantly lower than that measured at the deeper spots. Similarly, in the middle of the cavity, the peak polymerization temperature at the surface was significantly lower than that at the $4 \mathrm{~mm}$ depth, which was significantly lower than that at depths of $3 \mathrm{~mm}, 1 \mathrm{~mm}$, and 2 $\mathrm{mm}$ in an increasing order. Therefore, the second null hypothesis was rejected. This result is in contrast with another study reporting a higher polymerization temperature on the surface of the composite resin. In the study by Knezevic, et al. ${ }^{15}$ (2001), the polymerization temperature of the composite resin was higher on the surface than at the $1 \mathrm{~mm}$ depth. In their study, in order to simulate the composite resin layer of a depth of $1 \mathrm{~mm}$, a precured composite resin overlay of $1 \mathrm{~mm}$ thickness was placed above the uncured composite material samples of $0.1 \mathrm{~mm}$ thickness and light cured for $40 \mathrm{~s}$ through the overlay. Thus, only a small mass of the composite resin was used to measure the polymerization temperature compared to a large mass of composite resin used in our study. As described before, the difference in the mass of the composite resin resulted in the difference in the peak polymerization temperature at the 1 $\mathrm{mm}$ depth. Also, the lower peak polymerization temperature at the surface could be explained by the low heating effect of the LED LCU ${ }^{10}$ unlike the previous report of halogen LCUs with heat generation from the light source ${ }^{2}$. The higher peak polymerization temperature at $1 \mathrm{~mm}$ to 3 $\mathrm{mm}$ depth in the middle of the cavity could be 
explained as follows. Most studies measured the polymerization temperature on the lower surface of the composite resin of various thicknesses $5,15,21,24$. With this experimental design, the free radical of the composite resin monomer is located at the lower surface of the composite resin and it can find possible reaction partners only in the inner side of a hypothetical sphere centered on the free radical. In this study, however, the polymerization temperature of a large bulk of composite resin was measured on the upper surface while the proximal surface of the composite resin was light activated. In the bulk of the material, especially in the middle of the cavity, the free radical is three-dimensionally surrounded by possible reaction partners ${ }^{10}$, thus increasing the temperature rise in the bulk of the composite resin compared to the outer side of the material. Although the power density of the curing light is higher at the outer surface of the composite resin, the limited amount of monomers induced a low peak polymerization temperature. In addition, the low peak polymerization temperature at $4 \mathrm{~mm}$ depth in the middle of the cavity could be explained by the limited access of curing light to the deeper part of the composite resin. This situation is the opposite to that of the surface, since the amount of monomers is sufficient for polymerization, whereas the power density of the LCU reaching deep inside the composite resin is low. Therefore, composite resin of a depth of $1 \mathrm{~mm}$ to $3 \mathrm{~mm}$ seems to be favorable for light curing considering the factors such as access to the curing light and sufficiency of the monomers. These findings could be applied to situations such as bulk curing of the composite resin. As previously shown, bulk curing of the composite resin over $3 \mathrm{~mm}$ thickness could result in decreased polymerization due to limited curing light penetration of the composite resin itself ${ }^{8}$. Therefore, the clinician should consider incremental curing in deeper cavities.

The peak polymerization temperature measured in the middle of the cavity was significantly higher than that measured adjacent to the cavity wall at the same curing depth. This can also be explained by the less availability of monomers adjacent to the cavity wall than in the middle of the cavity for further polymerization as described above.

There are limitations of this study. Although this study was based on the concept that the temperature rise during light curing of the composite resin is a function of the rate and degree of conversion ${ }^{2,8}$, demonstration of the degree of cure by microhardness testing would have been more supportive. Also, Teflon molds were used instead of human tooth specimens when the peak temperature of the composite resin was measured. In addition, as the composite resin was not bonded to the Teflon molds, the composite resin was expected to shrink away from the cavity. With dentin bonding to the tooth structure, the polymerization of the composite resin might have the polimerization of the composite resin adjacent to the cavity wall might have been interfered. However, Hannig and Bott $^{9}$ (1999) reported that there was no significant difference between the pulp chamber temperature during composite resin polymerization with and without dentin bonding application in human tooth specimens. Therefore, the effect of dentin bonding on the peak temperature of composite resin polymerization might be negligible in this study.

\section{CONCLUSIONS}

Considering the limitations of this study, there were no statistically significant differences in the peak polymerization temperature of the composite resin according to various light curing modes. While analyzing the measurement spots adjacent to the cavity wall, the peak polymerization temperature at the depths of $1 \mathrm{~mm}$ to $4 \mathrm{~mm}$ was significantly higher than that of the surface. In the middle of the cavity, the peak polymerization temperature at the depths of $1 \mathrm{~mm}$ to $3 \mathrm{~mm}$ was significantly higher than that at the depth of $4 \mathrm{~mm}$, and that on the surface. Peak polymerization temperature of the spots in the middle of the cavity was higher than that measured in the spots adjacent to the cavity wall at all curing depths.

\section{ACKNOWLEDGEMENTS}

This study was supported by a grant (CRI 120471) Chonnam National University Hospital Research Institute of Clinical Medicine.

\section{REFERENCES}

1- Aguiar FH, Oliveira TR, Lima DA, Paulillo LA, Lovadino JR. Effect of light curing modes and ethanol immersion media on the susceptibility of a microhybrid composite resin to staining. J Appl Oral Sci. 2007; 15:105-9.

2- Al-Qudah AA, Mitchell CA, Biagioni PA, Hussey DL. Thermographic investigation of contemporary resin-containing dental materials. J Dent. 2005;33:593-602.

3- Al-Qudah AA, Mitchell CA, Biagioni PA, Hussey DL. Effect of composite shade, increment thickness and curing light on temperature rise during photocuring. J Dent. 2007;35:238-45.

4- Cekic-Nagas I, Ergun G. Effect of different light curing methods on mechanical and physical properties of resin-cements polymerized through ceramic discs. J Appl Oral Sci. 2011;19:40312.

5- Cobb DS, Dederich DN, Gardner TV. In vitro temperature change at the dentin/pulpal interface by using conventional visible light versus argon laser. Lasers Surg Med. 2000;26:386-97.

6- Cunha LG, Alonso RCB, Souza EJC, Neves AC, Correr-Sobrinho $L$, Sinhoreti MAC. Influence of the curing method on the postpolymerization shrinkage stress of a composite resin. J Appl Oral Sci. 2008;16:266-70. 
7- Davidson CL, Feilzer AJ. Polymerization shrinkage and polymerization shrinkage stress in polymer-based restoratives. J Dent. 1997;25:435-40.

8- Emami N, Söderholm KJ, Berglund LA. Effect of light power density variations on bulk curing properties of dental composites. J Dent. 2003;31:189-96.

9- Hannig M, Bott B. In-vitro pulp chamber temperature rise during composite resin polymerization with various light-curing sources. Dent Mater. 1999;15:275-81.

10- Hofmann N, Hugo B, Klaiber B. Effect of irradiation type (LED or QTH) on photo-activated composite shrinkage strain kinetics, temperature rise, and hardness. Eur J Oral Sci. 2002;110:471-9. 11- Hubbezoglu I, Dogan A, Dogan OM, Bolayir G, Bek B. Effects of light curing modes and resin composites on temperature rise under human dentin: an in vitro study. Dent Mater J. 2008;27:581-9. 12- Hussey DL, Biagioni PA, Lamey PJ. Thermographic measurement of temperature change during resin composite polymerization in vivo. J Dent. 1995;23:267-71.

13- Kanca J $3^{\text {rd }}$, Suh BI. Pulse activation: reducing resin-based composite contraction stresses at the enamel cavosurface margins. Am J Dent. 1999;12:107-12.

14- Kleverlaan CJ, de Gee AJ. Curing efficiency and heat generation of various resin composites cured with high-intensity halogen lights. Eur J Oral Sci. 2004;112:84-8.

15- Knezević A, Tarle Z, Meniga A, Sutalo J, Pichler G, Ristić M. Degree of conversion and temperature rise during polymerization of composite resin samples with blue diodes. J Oral Rehabil. 2001;28:586-91.

16- McCabe JF. Cure performance of light-activated composites by differential thermal analysis (DTA). Dent Mater. 1985;1:231-4. 17- Mehl A, Hickel R, Kunzelmann KH. Physical properties and gap formation of light-cured composites with and without "softstartpolymerization". J Dent. 1997;25:321-30.

18- Pereira JC, D'Alpino PHP, Lopes LG, Franco EB, Mondelli $\mathrm{RFL}$, Souza JB. Evaluation of internal adaptation of Class $V$ resin composite restorations using three techniques of polymerization. J Appl Oral Sci. 2007;15:49-54.
19- Rueggeberg FA, Caughman WF, Chan DC. Novel approach to measure composite conversion kinetics during exposure with stepped or continuous light-curing. J Esthet Dent. 1999;11:197205.

20- Sahafi A, Peutzfeldt A, Asmussen E. Effect of pulse-delay curing on in vitro wall-to-wall contraction of composite in dentin cavity preparations. Am J Dent. 2001;14:295-6.

21- Shortall AC, Harrington E. Temperature rise during polymerization of light-activated resin composites. J Oral Rehabil. 1998;25:908-13.

22- Stewardson DA, Shortall AC, Harrington E, Lumley PJ. Thermal changes and cure depths associated with a high intensity light activation unit. J Dent. 2004;32:643-51.

23- Suh BI, Feng L, Wang Y, Cripe C, Cincione F, de Rjik W. The effect of the pulse-delay cure technique on residual strain in composites. Compend Contin Educ Dent. 1999;20:4-12; quiz 13-4. 24- Uhl A, Mills RW, Jandt KD. Polymerization and light-induced heat of dental composites cured with LED and halogen technology. Biomaterials. 2003;24:1809-20.

25- Vaidyanathan J, Vaidyanathan TK. Computer-controlled differential scanning calorimetry of dental composites. IEEE Trans Biomed Eng. 1991;38:319-25.

26- Vaidyanathan J, Vaidyanathan TK, Wang Y, Viswanadhan T. Thermoanalytical characterization of visible light cure dental composites. J Oral Rehabil. 1992;19:49-64.

27- Yap AU, Ng SC, Siow KS. Soft-start polymerization: influence on effectiveness of cure and post-gel shrinkage. Oper Dent. 2001;26:260-6.

28- Zach L, Cohen G. Pulp response to externally applied heat. Oral Surg Oral Med Oral Pathol. 1965;19:515-30.

29- Zanchi CH, Carvalho RV, Rodrigues Junior SA, Demarco FF, Burnett Junior LH. Shrinkage stress of three composites under different polymerization methods. Braz Oral Res. 2006;20:137-42. 